\title{
Épocas de Poda na Cultura da Mandioca na Região Noroeste do Paraná, Brasil
}

\author{
Mário Takahashi \\ Instituto Agronômico do Paraná (IAPAR). Estação Experimental de Paranavaí, PR. Caixa Postal: 564, CEP: \\ 87701-970, Paranavaí, PR, Brasil.
}

\begin{abstract}
This work was undertaken with the objetive of evaluating the effect of pruning the aerial part in three distinct times upon the culture of cassava. All treatments were planted in October, 1991. In 1992, the canops pruned in three different times: May, June and July. A control treatment was cultivated without pruning. In May, 1993, all treatment were harvested. In comparision with the control, the three times of pruning resulted in alterations that modified the productions of fresh and dry root and canops matter as well was the harvest index. The final stand and the number of roots per plant were not altered by pruning. The differences in the production of canops on the pruning were altered due to the great variability in quantity of leaves.
\end{abstract}

Key words: Manihot esculenta; cassava; pruning; stems.

\section{INTRODUÇÃO}

A cultura da mandioca (Manihot esculenta Crantz), no Paraná, ocupou cento e trinta e oito mil hectares, com uma produção de dois milhões e novecentos e oito mil toneladas de raízes em 1997. Parte desta produção foi destinada ao processamento industrial em 180 farinheiras e 41 fecularias localizadas, principalmente, nas regiões Oeste e Noroeste do Estado (SEAB, 1998).

Nas regiões do Estado, onde as raízes de mandioca destinam-se às indústrias, as lavouras colhidas entre 18 e 24 meses têm a parte aérea podada aos 10-12 meses, para obtenção do material de propagação, ou para facilitar futuras práticas culturais, principalmente, a capina.

A poda pode ser necessária, na colheita, para facilitar esta operação. Neste caso é desejável o arrancamento imediato das raízes, pois o amido poderá ser utilizado como fonte de energia para nova brotação, à semelhança das sementes amiláceas (Lorenzi et al., 1978). Também a poda pode ser necessária para diminuir a fonte de inóculo de pragas e doenças. Para tanto, a melhor época é o período de redução da atividade fotossintética da planta (EMBRATER, 1976), que nas condições da região Centro Sul do Brasil ocorre a partir de maio, com a queda das temperaturas.

Os resultados da poda dependem da época em que é realizada, das condições climáticas e da idade das plantas. Segundo Mella (1988), a produção de raízes aumentou com a poda no inverno e diminuiu com a poda no verão, em relação a testemunha sem poda. Para Corrêa $e t$ al. (1973), a poda efetuada três meses antes da colheita, não reduziu a produção em relação a testemunha sem poda. Belarmino Filho (1986), observou que a poda no inverno, em junho, em função do ano agrícola, não alterou ou reduziu a produção de raízes. Furtado \& Corrêa (1988), podaram as plantas aos quatro meses após o plantio e na colheita com doze meses, obtiveram uma produção de raízes, semelhantes às sem poda. Na colheita aos dezoito meses, a poda estimulou a produção da parte aérea, em detrimento da produção de raízes.

A poda também reduziu o grau de deterioração fisiológica das raízes quando foi realizada aos 21 e 28 dias antes da colheita (Kato et al., 
1991). Para Santiago (1985), a poda efetuada aos 25 dias antes da colheita, não influenciou a produção de raízes e diminuiu a deterioração fisiológica das mesmas.

Em cada época de poda, a composição química da parte aérea, variou em função da idade das plantas, da quantidade de folhas (Carvalho \& Kato, 1987), da cultivar e da época do ano (Tiesehausen, 1987). Para Asaoka et al. (1993), a poda realizada quatro semanas antes da colheita, diminuiu o tamanho dos grânulos de amido das raízes, mas não afetou as suas propriedades físico-químicas.

Face ao exposto, o objetivo deste trabalho foi avaliar o efeito da poda da parte aérea em diferentes épocas, sobre alguns componentes de produção da cultura da mandioca, nas condições específicas de clima, solo e cultivar, na região Noroeste do Paraná.

\section{MATERIAL E MÉTODOS}

O experimento foi realizado no município de Paranavaí, PR, localizado na latitude $23^{\circ} 05^{\prime} \mathrm{S}$ e longitude $42^{\circ} 26^{\prime} \mathrm{W}$, com altitude de $480 \mathrm{~m}$ acima do nível do mar, no período de outubro de 1991 a maio de 1993. O experimento foi instalado em um solo, constituído, de 0 a $20 \mathrm{~cm}$ de profundidade, de $89 \%$ de areia, $1 \%$ de silte e $10 \%$ de argila, classificado como Podzólico Vermelho Amarelo distrófico segundo a EMBRAPA (1984). A análise química do solo foi realizada conforme metodologias descritas por Pavan et al. (1992), e os resultados encontram-se na Tabela 1 . $\mathrm{O}$ experimento foi conduzido sem adubação, para reproduzir as condições médias em que a mandioca é cultivada na região.

O tipo climático predominante na região é o Cfa, subtropical úmido mesotérmico, segundo a classificação de Koeppen e que se caracteriza pela predominância de verões quentes, baixa freqüência de geadas severas e tendência de concentração de chuvas no verão. Os dados da precipitação pluviométrica e das temperaturas médias mensais, durante a realização do experimento, encontram-se na Fig. 1.

A cultivar de mandioca utilizada foi a regionalmente conhecida como Fibra, de parte aérea ereta, raízes tuberosas curtas e de casca clara, uma das mais plantadas na região e destinada ao processamento industrial.

O espaçamento utilizado foi de $0,8 \mathrm{~m}$ entre as linhas e $0,6 \mathrm{~m}$ entre as plantas, compondo uma população de 20830 plantas/ha. As manivas ou estacas, com um ciclo de idade, $15 \mathrm{~cm}$ de comprimento e no mínimo com cinco gemas, foram plantadas manualmente, na posição horizontal ao terreno, dentro de sulcos com 10 $\mathrm{cm}$ de profundidade, abertos com um sulcador, acoplado a um trator.

Em outubro de 1991, todos os tratamentos foram plantados. Em maio, julho e outubro de 1992 (sete, nove e doze meses após o plantio) podaram-se as plantas a $30 \mathrm{~cm}$ de altura do solo. A testemunha foi conduzida sem poda. A colheita foi realizada em maio de 1993.

Tabela 1. Análise de solo, da área experimental em amostra coletada entre 0 a $20 \mathrm{~cm}$ de profundidade. Paranavaí, PR. 1991/93.

\begin{tabular}{cccccccc}
\hline $\begin{array}{c}\mathrm{pH} \\
\mathrm{CaCl}_{2}\end{array}$ & $\begin{array}{c}\mathrm{Al} \\
\mid--\end{array}$ & $\mathrm{H}+\mathrm{Al}$ & $\begin{array}{c}\mathrm{Ca} \\
----\end{array} \mathrm{cmol}_{\mathrm{c}} / 100 \mathrm{dm}^{3}$ & $\mathrm{Mg}$ & $\mathrm{K}$ & $\begin{array}{c}\mathrm{P} \\
\mathrm{mg} / \mathrm{dm}^{3}\end{array}$ & $\begin{array}{c}\mathrm{C} \\
\mathrm{g} / \mathrm{dm}^{3}\end{array}$ \\
\hline 4,6 & 0,12 & 3,33 & 1,54 & 0,70 & 0,21 & 1,90 & 0,93 \\
\hline
\end{tabular}




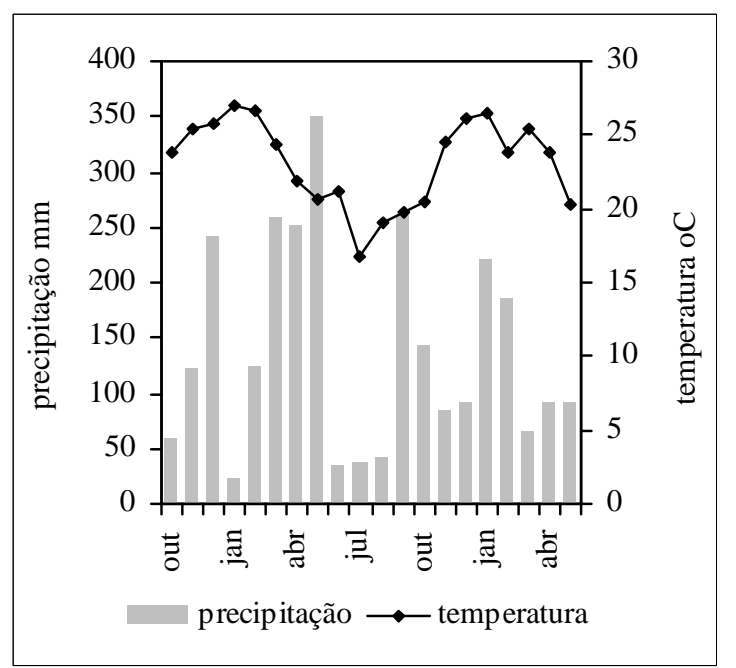

Figura 1- Precipitação pluviométrica e temperaturas médias mensais, durante a realização do experimento.

As parcelas de 21,6 $\mathrm{m}^{2}$, foram compostas por cinco linhas de nove plantas por linha. $\mathrm{Na}$ área útil de cada parcela, foram avaliadas 21 plantas. $\mathrm{O}$ delineamento foi em blocos ao acaso com três repetições.

A população de plantas inicial, foi avaliada 30 dias após o plantio. Em cada época de poda, foram avaliadas a produção fresca e a matéria seca da parte aérea, proteína bruta, cálcio e fósforo. $\mathrm{Na}$ colheita, foram avaliadas as produções fresca e seca das raízes, frescas das cepas e da parte aérea, população de plantas final, número de raízes tuberosas por planta e índice de colheita. A parte aérea foi considerada $30 \mathrm{~cm}$ acima do solo e as cepas, a porção restante da planta, retirando-se as raízes tuberosas. O índice de colheita, seguiu a relação das produções frescas: raízes $\mathrm{x}$ (parte aérea + cepas + raízes $)^{-1}$. A parte aérea para o cálculo deste índice, foi somente a da colheita. A matéria seca das raízes, foi determinada, segundo metodologia descrita por Grossman \& Freitas (1950).

$\mathrm{Na}$ a análise de variância, foram considerados três tratamentos na poda e quatro na colheita, neste caso devido a testemunha, conduzida sem poda.

\section{RESULTADOS E DISCUSSÃO}

\section{Poda}

As épocas em que as podas foram realizadas, não alteraram as produções e a matéria seca das ramas. Estes resultados mostraram que as ramas em maio, encontravam-se plenamente desenvolvidas e não aumentaram a produção, em relação às de julho e outubro (Tabela 2).

Em maio, a parte aérea apresentou significativamente mais folhas que em julho e em outubro, em função da queda natural das mesmas, devido à redução das temperaturas do ar (Fig. 1). As proporções de folhas em relação ao total da parte aérea, decresceram de $40,97 \%$ em maio, para 6,76\% em julho e 6,37\% em outubro. Entre julho e outubro, não houve tempo suficiente para a recuperação das folhas das plantas, em função da nova brotação.

Em maio e julho, as folhas eram mais velhas e as de outubro, provenientes da nova brotação, eram mais tenras, com menor percentual de matéria seca. As ramas e as folhas podadas em julho e outubro, apresentaram produções, significativamente menores que às de maio. A superioridade em maio, foi devido a maior quantidade de folhas. Resultados semelhantes foram obtidos por Corrêa et al. (1973), em épocas de poda e condições climáticas próximas às do experimento.

Nas três épocas de poda houve variações nos teores de proteína bruta. Os maiores valores encontrados na parte aérea das plantas podadas em maio, foi devido a maior proporção de folhas (Tabela 3). Estes resultados, foram semelhantes aos de Carvalho \& Kato (1987), que encontraram maior concentração de proteína bruta nas folhas. Devido a nova brotação, que enriqueceu a parte aérea, os teores de proteína bruta não diferiram entre maio e outubro. Contudo, esta nova brotação de outubro, foi insuficiente para aumentar a proteína bruta, em relação à obtida em julho. 
Tabela 2. Produção fresca da parte aérea em t/ha, dividida em ramas, folhas e ramas + folhas e suas respectivas matérias secas em \%, nas três épocas de poda. Paranavaí, PR. 1991/93.

\begin{tabular}{|c|c|c|c|c|c|c|c|c|c|c|}
\hline \multirow[t]{2}{*}{ Poda } & \multicolumn{3}{|c|}{ Ramas } & & \multicolumn{3}{|c|}{ Folhas } & & \multicolumn{2}{|c|}{ Ramas + Folhas } \\
\hline & frescas & & $\begin{array}{c}\text { matéria } \\
\text { seca }\end{array}$ & & Frescas & & $\begin{array}{c}\text { matéria } \\
\text { seca }\end{array}$ & & & \\
\hline Maio & 5,39 & $\mathrm{a}$ & 21,71 & $\mathrm{a}$ & 3,74 & $\mathrm{a}$ & 29,29 & $\mathrm{a}$ & 9,13 & $a^{*}$ \\
\hline Julho & 4,82 & $\mathrm{a}$ & 19,07 & $\mathrm{a}$ & 0,35 & $\mathrm{~b}$ & 23,40 & $\mathrm{~b}$ & 5,17 & $\mathrm{~b}$ \\
\hline Outubro & 4,70 & $\mathrm{a}$ & 19,21 & $\mathrm{a}$ & 0,32 & $\mathrm{~b}$ & 16,94 & $\mathrm{c}$ & 5,02 & $\mathrm{~b}$ \\
\hline Média & 4,97 & & 19,99 & & 1,47 & & 23,21 & & 6,44 & \\
\hline $\mathrm{CV}^{* *}$ & 6,93 & & 5,84 & & 4,39 & & 5,60 & & 5,74 & \\
\hline
\end{tabular}

Médias nas colunas seguidas das mesmas letras, não diferem estatisticamente entre si a $5 \%$ pelo teste de T. ** Coeficiente de variação $(\%)$.

Carvalho \& Kato (1987), observaram um aumento de $10,22 \%$ para $20,69 \%$ nos teores de proteína bruta da parte aérea, quando estas foram obtidas em julho e em novembro, devido a uma nova brotação e a uma maior quantidade de folhas.

Os teores de fósforo e cálcio não sofreram variações entre as épocas, mesmo com diferentes proporções das ramas, em relação as folhas. Os resultados indicaram, maior concentração desses elementos nas ramas, pois a parte aérea, em maio, mesmo com maior proporção de folhas, apresentou teores semelhantes às de julho e outubro (Tabela 3 ). Os teores de fósforo, estão próximos aos obtidos por Tiesenhausen (1987), que também encontrou poucas variações nos teores, em análises realizadas em diferentes porções da parte aérea.

\section{Colheita}

As épocas de poda, alteraram as produções fresca e seca das raízes na colheita (Tabela 4). A poda, em maio, proporcionou um efeito positivo na produção de raízes frescas, em relação à de julho, mesmo retirando-se $76,6 \%$ a mais de parte aérea. Não houve diferenças entre as podas de maio, outubro e a testemunha sem poda. As produções de raízes secas foram favorecidas, após as podas realizadas em maio e outubro, em relação à realizada em julho e sem poda. Os percentuais de matéria seca foram alterados pela poda, acentuando-se as diferenças obtidas nas produções das raízes frescas. Resultados distintos foram obtidos por Mella (1988), que obteve uma maior produção de raízes em relação a testemunha sem poda após a poda realizada em julho, no inverno. Para Corrêa et al. (1973), as produções de raízes frescas foram semelhantes, nas podas efetuadas seis, nove e doze meses após o plantio.

As produções da parte aérea e das cepas frescas, na colheita, não apresentaram diferenças estatísticas entre os tratamentos (Tabela 5). As recuperações da parte aérea, entre as três épocas de poda até a colheita, foram semelhantes.

A população de plantas inicial, 30 dias após o plantio, foi de $100 \%$ em todos os tratamentos. A população de plantas final na colheita, apresentou reduções de 8,7 a $16,8 \%$, em relação ao previsto de 20.830 plantas/ha, mas sem diferenças estatísticas entre os tratamentos.

O índice de colheita após a poda, em maio, foi significativamente maior em relação a testemunha, ou seja, aumentou-se a proporção de raízes frescas em relação ao total produzido pela planta. (Tabela 6). Entre as três épocas de poda, os índices de colheita foram semelhantes. Furtado \& Corrêa (1988), também obtiveram 
índice de colheita superior, em relação à testemunha, após oito meses da poda.

Tabela 3. Proteína bruta, fósforo e cálcio em $\%$ da parte aérea, nas três épocas de poda. Paranavaí, PR. 1991/93.

\begin{tabular}{lrlll}
\hline Poda & $\begin{array}{r}\text { Proteína } \\
\text { bruta }\end{array}$ & P & Ca \\
\hline maio & 13,94 a & $0,12 \mathrm{a}$ & $1,23 \mathrm{a}^{*}$ \\
julho & 9,41 & $\mathrm{~b}$ & $0,10 \mathrm{a}$ & $1,33 \mathrm{a}$ \\
outubro & 12,17 & ab & $0,11 \mathrm{a}$ & $1,19 \mathrm{a}$ \\
\hline média & 11,84 & 0,11 & 1,25 \\
$\mathrm{CV}^{* *}$ & 12,14 & 20,07 & 8,16 \\
\hline
\end{tabular}

Tabela 4. Produções na colheita, das raízes fresca e seca em t/ha, após a poda e sem poda. Paranavaí, PR. 1991/93.

\begin{tabular}{lclll}
\hline Poda & $\begin{array}{c}\text { Raízes } \\
\text { frescas }\end{array}$ & \multicolumn{3}{c}{$\begin{array}{c}\text { Raízes } \\
\text { secas }\end{array}$} \\
\hline maio & 47,80 & $\mathrm{a}$ & 17,33 & $\mathrm{a}^{*}$ \\
julho & 33,70 & $\mathrm{~b}$ & 11,73 & $\mathrm{~b}$ \\
outubro & 42,43 & $\mathrm{ab}$ & 15,36 & $\mathrm{a}$ \\
sem poda & 34,66 & $\mathrm{ab}$ & 12,26 & $\mathrm{~b}$ \\
\hline média & 39,65 & & 14,17 & \\
CV** & 12,41 & & 10,13 & \\
\hline
\end{tabular}

Tabela 5. Produções na colheita, das cepas e da parte aérea frescas em t/ha, após a poda e sem poda. Paranavaí, PR. 1991/93.

\begin{tabular}{lrlrl}
\hline Poda & Cepas & \multicolumn{3}{r}{$\begin{array}{r}\text { Parte } \\
\text { aérea }\end{array}$} \\
\hline maio & 11,75 & a & 8,56 & a $^{*}$ \\
julho & 9,84 & a & 7,10 & a \\
outubro & 10,79 & a & 11,10 & a \\
sem poda & 10,41 & a & 10,47 & a \\
\hline média & 10,70 & & 9,31 & \\
CV $^{* *}$ & 19,33 & & 18,68 & \\
\hline
\end{tabular}

Os tratamentos não alteraram estatisticamente o número de raízes tuberosas por planta (tabela 6). Belarmino Filho (1986), obteve resultados semelhantes com relação ao número de raízes, com a poda efetuada em junho, no inverno.

Os resultados obtidos neste trabalho e de outros autores, mostraram que a prática da poda, depende muito do clima, da cultivar de mandioca e da época em que é realizada. No caso da região em questão, poderá ser adotada como uma operação, que venha a favorecer futuras práticas culturais, em lavouras que serão colhidas com mais de um ciclo, sem prejuízo na produção de raízes.

Tabela 6. Índice de colheita em \% e número de raízes tuberosas por planta na colheita, após a poda e sem poda. Paranavaí, PR. 1991/93.

\begin{tabular}{lclrl}
\hline Poda & $\begin{array}{c}\text { Índice } \\
\text { colheita }\end{array}$ & \multicolumn{3}{c}{$\begin{array}{c}\text { № raízes/ } \\
\text { planta }\end{array}$} \\
\hline Maio & 70,10 & a & 7,76 & $\mathrm{a}^{*}$ \\
Julho & 66,96 & ab & 5,96 & a \\
Outubro & 65,76 & ab & 7,60 & a \\
sem poda & 62,26 & b & 7,26 & a \\
\hline Média & 66,27 & & 7,14 & \\
CV** & 3,88 & & 18,68 & \\
\hline
\end{tabular}

*Médias nas colunas seguidas das mesmas letras, não diferem estatisticamente entre si a 5\% pelo teste de T. **Coeficiente de variação (\%).

\section{RESUMO}

Este trabalho teve por objetivo avaliar o efeito da poda da parte aérea, realizada em três épocas distintas, sobre alguns parâmetros fitotécnicos da mandioca (Manihot esculenta Crantz). Todos os tratamentos foram plantados em outubro de 1991. Em 1992, efetuaram-se as podas da parte aérea em maio, julho e outubro. A testemunha foi conduzida sem poda. Em maio de 1993, todos os tratamentos foram colhidos. As produções da parte aérea na poda, foram alteradas pela quantidade de folhas. As produções fresca e seca das raízes e da parte aérea e o índice de colheita, foram modificados após a poda, em relação ao tratamento sem 
poda. O stand final e o número de raízes por planta, não foram alterados pela poda.

\section{REFERÊNCIAS BIBLIOGRÁFICAS}

Asaoka, M; Blanshard, J.M.V; Rickard,J.E. (1993). The effect of pre-harvest pruning on the quality of cassava starch. Annals of Applied Biology, 122, 337-44.

Belarmino Filho, J. (1986). Efeito da poda e de diferentes sistemas de condução das plantas sobre a produção de raízes e ramas em algumas variedades de mandioca (Manihot esculenta Crantz). Dissertação Mestrado. Escola Superior de Agricultura de Lavras. Lavras.

Carvalho, V.D \& Kato, M.S.A. (1987). Potencial de utilização da parte aérea da mandioca. In: Mandioca: possibilidades de utilização. Informe Agropecuário, 13, 23-8.

Correa, H, Begazo, J.C.E.O, Brandão, S.S (1973). Efeito da poda de ramas de mandioca na produção de ramas e raízes. CERES, 20 , 148-53

Embrapa - Empresa Brasileira de Pesquisa Agropecuária (1984). Serviço Nacional de Levantamento e Conservação de Solos. Levantamento de reconhecimento dos solos do estado do Paraná. Curitiba. (EMBRAPASNLCS, Boletim técnico, 57).

Embrater - Empresa Brasileira de Assistência Técnica e Extensão Rural. (1976). Sistemas de produção para a mandioca. Brasília. EMBRATER, 36 p. (Série Sistemas de produção, $\mathrm{n}^{\mathrm{o}}$.15).

Furtado M.C \& Correa,.H. (1988). Influência da poda no comportamento de seis variedades de mandioca (Manihot esculenta Crantz) no estado do Espírito Santo. Ciência e Prática. 12, 55-65.
Grossman, J \& Freitas, A.C (1950). Determinação do teor de matéria seca pelo peso específico em raízes de mandioca. Revista Agronômica, 14, 75-80.

Kato, M.S.A, Carvalho, V.D \& Corrêa, H. (1991). Efeito da poda na deterioração fisiológica, atividade enzimática e nos teores de compostos fenólicos em raízes de mandioca. Pesq. Agropec. Bras., 26, 237-45.

Lorenzi, J.O, Gutierrez, L.E \& Normanha, E.S. (1978).Variação de carboidratos e ácido cianídrico em raízes de mandioca após a poda da parte aérea. Bragantia, 37, 137-44.

Mella, S.C. (1988). Efeito de diferentes épocas de poda sobre a produção de raízes e parte aérea de mandioca. $5^{\circ}$ Congresso Brasileiro de Mandioca. Anais..., 53. Fortaleza.

Pavan, M.A; Bloch, M.A; Zempulski, H.C; Miyazawa, M \& Zocoler, D.C. (1992). Manual de análise química de solo $e$ controle de qualidade. IAPAR,. $40 \mathrm{p}$. (IAPAR, Circular, $\mathrm{n}^{\mathrm{0}}$ 76).

Santiago, A.D. (1985). Efeito da poda na produtividade, conservação e qualidade de raízes de mandioca (Manihot esculenta Crantz). Dissertação Mestrado. Escola Superior de Agricultura de Lavras. Lavras.

SEAB- Secretaria de Estado da Agricultura e do Abastecimento do Paraná. Departamento de Economia Rural (1998). Sistema de acompanhamento de safra subjetiva. 2p.

Tiesenhausen, IME.V. (1987). O feno e a silagem da rama de mandioca na alimentação de ruminantes. In: Mandioca: possibilidades de utilização. Informe Agropecuário. 13, 42-6.
Received: March 19, 1998; Revised: March 30, 1998; Accepted: June 10, 1998. 